\title{
ALTERNATIF MEDIA KOMUNIKASI VISUAL DALAM PRAKTEK PEMBELAJARAN KESEHATAN DI PUSAT LAYANAN MASYARAKAT BERBASIS ICT
}

\author{
Oleh: Muhammad Ashar *) dan Syaad Patmanthara **
}

\section{Abstrak}

Pembelajaran kesehatan di posyandu saat ini perlu dikembangkan guna mendukung program pemerintah menuju Indonesia sehat $\mathbf{2 0 1 0}$ melalui konsep ICT (informatics Communication and Technology). Dukungan dari penyuluh atau pendamping kesehatan pada posyandu dengan memanfaatkan media pembelajaran dalam memberikan informasi kesehatan khusunya pada ibu dan anak pada posyandu melalui program telecenter, komuniasi visual dan hybrid e-learning dan e-health. Pendayagunaan resousce kesehatan pada posyandu dengan dukungan teknologi informasi akan memudahkan penyampaian informasi kesehatan secara tepat sasaran terutama mengenai informasi hidup sehat, Pertolongan keselamatan ibu dan anak, Pendidikan anak usia dini, Program keluarga berencana, Penyakit dan penanganannya serta kesehatan lingkungan.Pembuatan konten pembelajaran kesehatan diharapkan memiliki unsur pendidikan dengan konsep praktek pembelajaran berbantuan teknologi informasi yang diproduksi dalam bentuk CD interaktif, Video Animasi dan Website yang dapat di akses secara online. Dengan penerapan infomobilisasi diharapkan rekomendasi untuk melalukan perubahan minset pada teknik pembelajaran kesehatan di posyandu adalah salah satu upaya dalam mencerdaskan masyarakat sebagai bagian dari "ICT for Society".

Kata kunci: Infomobilisasi, ICT, CD Interaktif, ICT for Society, e-learning, e-health

\section{PENDAHULUAN}

Infomobilisasi merupakan program informasi dan komunikasi yang bertujuan melakukan perubahan masyarakat menuju masyarakat berpengetahuan (knowledge society) yang lebih sejahtera. Infomobilisasi dikembangkan sebagai rangkaian kegiatan yang melibatkan masyarakat secara aktif (partisipatif) dalam menggali permasalahan, kebutuhan, potensi, dan struktur komunikasi dan informasi yang dapat mendorong perbaikan kehidupan mereka.

Penerapan infomobilisasi secara khusus dapat digunakan dengan konsep rekomendasi media
ICT dalam metode pembelajaran kesehatan yang di fokuskan untuk posyandu perlu dilakukan pengujian sebagai pertimbangan dalam menyusun program startegi yang tepat sasaran melalui sarana dan media yang dirancang untuk memudahkan kelompok masyarakat terutama masyarakat miskin dalam mengolah informasi kesehatan yang dibutuhkan oleh mereka dengan melibatkan resource kesehatan yang terdidik melalui program pendampingan promosi kesehatan masyarakat.

*) Muhammad Ashar, ST., M.Kom., adalah Pengajar Prodi Pendidikan Teknik Informatika FT Universitas Negeri Malang

**) Dr. Ir. Syaad Patmanthara, adalah Pengajar Prodi Pendidikan Teknik Informatika FT Universitas Negeri Malang 
ICT dalam meningkatkan pembelajaran saat ini masih didominasi oleh intansi dan lembaga pendidikan. Kemajuan teknologi informasi yang didukung oleh sumber daya manusia (Resources) yang memiliki skil dengan professional merupakan modal yang sangat potensial dalam membangun kesejahteran masyarakat umum, namun kurangnya pemanfaatan ICT untuk masyarakat sosial selain dari penggunaan sebagai layanan informasi dan transfer dalam informasi dengan sistem komunikasi jarak jauh menjadikan layanan ICT kurang dirasakan oleh masyarakat terutama yang berada pada daerah pedesaan. Pengembangan internet masuk desa dan terdapatnya teknologi wireless (wifi dan wimax) memberikan kesempatan yang sangat tinggi dalam memudahkan layanan masyarakat terutama bila digunakan sebagai media pembelajaran kesehatan selain teknologi media digital lainnya seperti Media Visual promosi kesehatan dan E-learning.

Salah satu program pemerintah yaitu menuju indonesia sehat 2010 dengan kegiatan mengoptimalkan posyandu sebagai kerangka awal proses pelayanan kesehatan anak sehingga diharapkan kecerdasan orang tua terutama para ibu Indonesia penting dalam hal pemberian informasi mengenai kesehatan ibu dan anak menyangkut masalah penyakit, gizi dan makanan serta kesehatan lingkungan hidup sehat dan bersih. Beberapa posyandu diberbagai pedesaan telah melakukan utilisasi TI dengan implementasi Sistem Informasi Pos Yandu (SIP) sebagai langkah awal dalam penggunaan ICT untuk kesehatan masyarakat di lingkungan posyandu. Implementasi sistem informasi posyandu merupakan upaya pemberdayaan posyandu dalam meningkatkan derajat kesehatan, perubahan prilaku dalam hidup sehat masih sulit dilakukan walaupun sarana ICT pada posyandu telah digunakan.Sehingga penting mengubah pola pikir atau mindset masyarakat dengan menempatkan posyandu bukan hanya sebagai layanan kesehatan tetapi juga terdapat layanan pedidikan melalui program pemberdayaan posyandu sebagai media pembelajaran kesehatan diluar pendidikan formal.

Berbagai media pembelajaran kesehatan misalnya buku elektronik kesehatan, konten elearning dan modul kesehatan banyak beredar pada internet atau blog yang tersimpan baik berbentuk teks, diagram maupun video interaktif merupakan peluang dan sumber pembelajaran yang menarik dikemas dalam pemanfaatan ICT untuk masyarakat melalui media pembelajaran yang tentunya setiap materi kesehatan harus diuji terdahulu atau mendapat rekomendasi oleh dinas kesehatan sesuai dengan standar kesehatan. Untuk mewujudkan metode KIE (Komunikasi, Informasi dan Edukasi) pada program revitalisasi posyandu dalam meningkatkan pemahaman masyarakat yang berkunjung ke posyandu maka perlu dicermati bagaimana merancang dan membuat media pembelajaran kesehatan melalui program "ICT for Society" dengan dukungan teknologi informasi yang saat ini telah mengalami perkembangan yang sangat cepat misalnya dengan adanya teknologi multimedia yang mampu mendukung kememungkinan terwujudnya program infomobilisasi kesehatan di posyandu.

Permasalahan yang dapat muncul adalah kesiapan lingkungan posyandu untuk mengubah paradigma masyarakat agar posyandu dapat melakukan aktifitas pembelajaran sedini mungkin dengan materi kesehatan yang selalu update, terencana dan termonitoring sesuai standard kesehatan yang wajib diketahui oleh masyarakat pengguna posyandu.

\section{KAJIAN LITERATUR}

Konsep yang disebut sebagai fasilitator infomobiliasasi dengan penggunaaan media ICT menjelaskan bahwa unsur pendampingan masyarakat yang memanfaatkan komunikasi informasi sebagai sumber-sumber pembelajaran untuk meningkatkan kualitas hidup masyarakat miskin, di dalam buku " panduan untuk fasilitator infomobilisasi Mengembangkan Media Komunikasi Berbasis Masyarakat " (Zulfikar Mochamad Rachman, Bappenas - UNDP Jakarta) dengan konsep terdapatnya dua gagasan dasar yang dipadukan dalam infomobilisasi sebagai bagian dari program pengentasan kemiskinan berbasis TIK, yaitu (1) Pengembangan komunikasi informasi dengan memperkuat mengenalkan TIK kepada masyarakat perdesaan, khususnya kelompok miskin dan perempuan; dan (2) Pemberdayaan masyarakat melalui kegiatan pendampingan dan kerjasama dengan program sektor lain ( kesehatan primer). 
Menurut wacana "Media Pembelajaran Kesehatan Komunitas" (PRO-HEALTH | November 16, 2009) Posyandu adalah alih teknologi dan pelayanan kesehatan masyarakat oleh dan untuk masyarakat yang mempunyai nilai strategis untuk mengembangkan sumber daya manusia sejak dini. Pemerintah mengupayakan mengaktifkan kembali kegiatan di posyandu, karena posyandulah tempat paling cocok untuk memberikan pelayanan kesehatan pada balita secara berkesinambungan dan terpadu. Pertama kali dikenalkan, Posyandu adalah tempat balita melakukan penimbangan dan bayi mendapatkan imunisasi. Seiring berjalannya waktu, peran Posyandu lebih dikembangkan. Posyandu merupakan suatu forum bersama lintas sektor (kesehatan, BKKBN/BKBKS, Pertanian, Peternakan, Perikanan, Pendidikan dan Pemerintahan) yang bertujuan untuk meningkatkan kemandirian masyarakat dibidang ekonomi, kesehatan dan pendidikan. Seharusnya, kegiatan-kegiatan yang dilaksanakan di Posyandu meliputi:

\section{Bidang kesehatan:}

- Penimbangan balita, termasuk pemberian makanan tambahan (PMT)

- Imunisasi pada bayi (meliputi : BCG, DPT, HB, Polio, dan Campak)

- Pemeriksaan Ibu Hamil

- Pemberian Paket Obat Gizi (Tablet tambah darah dan Kapsul Yodium untuk ibu hamil, Kapsul Vit. A untuk Bayi, Balita dan Ibu Nifas)

- Pelayanan kesehatan dasar

- Penyuluhan kesehatan

\section{Bidang KB:}

- Pelayanan kontrasepsi

- Pelayanan Papsmear gratis bagi kader posyandu

- Penyuluhan tentang KB.

3. Bidang Pertanian, peternakan, dan perikanan

- Penyuluhan tentang pemanfaatan lahan/ pekarangan dengan aneka tanaman dan ternak yang bisa memenuhi kebutuhan gizi keluarga secaramandiri.

\section{Bidang pemerintahan (Desa/Kelurahan)}

- Penyediaan sarana dan prasarana bagi kegiatan posyandu.

\section{Bidang Pendidikan}

- Penyediaan sarana dan prasarana KIE (komunikasi-informasi-edukasi) untuk Pendidikan Anak Usia Dini (PAUD)

Dengan demikian, apabila seluruh sektor terkait dapat ikut ambil bagian dalam kegiatan Posyandu, maka tujuan Posyandu sebagai ujung tombak pemberdayaan masyarakat bisa terwujud sehingga bisa diperoleh generasi penerus bangsa yang berkualitas tinggi. Dan tak kalah pentingnya adalah peran serta masyarakat sebagai sasaran pelayan Posyandu, agar mau memanfaatkan seluruh fasilitas yang telah disediakan.

Pemanfaatan posyandu sebagai media pembelajaran menurut artikel Optimalisasi Kader Posyandu untuk Pengembangan PAUD (Didi Mardianto: www.rumahcerdaskreatif .com) menjelaskan bahwa saat ini pemerintah tengah menggalakkan kembali Gerakan POSYANDU sebagai media yang digunakan untuk memantau dan memastikan Balita Indonesia tumbuh sehat sebagai langkah awal membentuk Manusia Indonesia yang cerdas, sehat dan terampil. Theme Song "Aku Anak Sehat " yang digunakan untuk sosialisasi Gerakan "Ayo ke Posyandu", menggambarkan keriangan anak Indonesia yang bangga dirinya Sehat karena memiliki tubuh kuat, sebab ibu mereka Rajin dan Cermat, dimana semasa bayi, selalu memberi ASI, makanan Bergizi dan Imunisasi, serta selalu menimbang Berat Badan karena Posyandu menunggu setiap waktu, dan dikala diare, ibu mereka selalu waspada, karena pertolongan oralit telah siap sedia, akan menjadi tidak bermakna apa-apa ketika asupan Gizi yang mereka dapatkan tidak berlanjut dan tidak diimbangi dengan Asupan Pendidikan dikala mereka kecil.

Kegiatan Posyandu pasti selalu diramaikan dengan ibu-ibu yang memiliki anak Balita. Balita itulah yang akan dijadikan sebagai target layanan dari POS PAUD. Silahkan lakukan quick survey di kalangan warga masyarakat yang memanfaatkan kehadiran Posyandu. Umumnya mereka yang datang ke Posyandu adalah warga masyarakat yang berasal dari kalangan bawah yang merasakan mahalnya biaya untuk mendapatkan akses sehat bagi anak-anak mereka dan lebih memilih datang ke posyandu gratis untuk memastikan anak-anak mereka tumbuh dengan baik dan sehat. 
Sementara itu hasil penelitian yang dilakukan oleh Sayekti Pranti dkk,(Dosen UM 2006) "Studi Tentang Pengetahuan dan Perilaku Gizi Ibu dalam Upaya Peningkatan Kesehatan Keluarga pada Anak Usia Pra Sekolah" Hasil yang diperoleh dalam penelitian ini antara lain, jumlah anak usia pra sekolah di desa Pendem mengalami gizi kurang. Faktor penyebab terjadinya gizi kurang pada balita di desa Pendem adalah penyebab langsung dan tidak langsung. Penyebab langsung yang dialami berasal dari makanan dan penyakit. Sedangkan penyebab tidak langsung antara lain ketersediaan pangan keluarga yang kurang memadai, pola pengasuhan anak yang kurang memadahi serta pelayanan kesehatan dan lingkungan sehat yang kurang memadai. Beberapa faktor penyebab di atas dilatarbelakangi oleh kurangnya pengetahuan ibu tentang gizi sehingga berakibat pada perilaku gizi ibu pada umumnya. Kurangnya pengetahuan yang dimiliki oleh sebagian besar ibu rumah tangga di desa Pendem merupakan akibat dari kurangnya informasi yang didapat baik dari posyandu maupun pos pelayanan kesehatan setempat, di samping faktor pendidikan yang dimiliki para ibu sangat rendah. Kondisi inipun diperburuk oleh faktor kemiskinan.

\section{KONSEP DAN DESAIN ICT LAYANAN KESEHATAN DI POSYANDU}

\section{Telecenter}

Desain telecenter sebagai pusat layanan informasi di posyandu dikembangkan guna memberikan layanan kesehatan dan pencapaian program posyandu. Pemanfaatan telecenter dengan media pembelajaran kesehatan sebagai sarana yang memungkinkan dalam mendistribusikan materi pembelajaran secara terpusat dan terkontrol yang dapat digunakan sewaktuwaktu atau terprogram. Akses Data dan Media Pembelajaran kesehatan terupdate dan terdapat link antar posyandu.

\section{Media Komunikasi visual}

Media adalah alat bantu apa saja yang dapat dijadikan sebagai penyalur pesan guna mencapai tujuan pembelajaran .Ada beberapa jenis media pembelajaran yang biasa digunakan dalam proses belajar mengajar. Pertama, media grafis seperti gambar, foto, grafik bagan atau diagram, poster, kartun, komik dan lain-lain. Media grafis sering juga dusebut media dua dimensi, yakni media yang mempunyai ukuran panjang dan lebar. Kedua, media tiga dimensi yaitu dalam betuk model seperti model padat (solid model), model penampang, model susun, model kerja, mock up, diorama dan lain - lain. Ketiga, media proyesi seperti slide, film strips, film, penggunaan OHP dan lain - lain. Keempat penggunaan lingkungan sebagai media pengajaran. ( Rivai, 1991:5).

Penggolongan media pembelajaran menurut Gerlach dan Ely ( 1997 : 16 ) yaitu :

- Gambar diam, baik dalam bentuk teks, buletin, papan display, slide film strip, atau overhead proyektor.

- Gambar gerak, baik hitam putih, berwarna, baik yang bersuara maupun yang tidak bersuara.

- Rekaman bersuara baik dalam kaset maupun piringan hitam.

- Televisi.

- Benda-benda hidup, simulasi maupun model.

- Instruksional berprograma ataupun CAI (Computer Assisten Instruction).

CD Interaktif adalah salah satu media interaktif yang bisa terbilang baru. Media ini sebenarnya merupakan pengembangan dari teknologi internet yang akhir-akhir ini berkembang pesat. CD Interaktif merupakan sebuah media yang menegaskan sebuah format multimedia dapat dikemas dalam sebuah CD (Compact Disk) dengan tujuan aplikasi interaktif di dalamnya. CD ROM (Read Only Memory) merupakan satusatunya dari beberapa kemungkinan yang dapat menyatukan suara, video, teks, dan program dalam CD (Tim Medikomp, 1994).

Kemudian dalam program talk show eLifestyle yang ditayangkan Metro TV pada 9 Agustus 2003 pukul 09.00 WIB disebutkan bahwa CD Interaktif adalah sebuah CD yang berisi menu-menu yang dapat diklik untuk menampilkan sebuah informasi tertentu. Dari sini jelas bahwa sistem interaktif yang dipakai CD Interaktif sama persis dengan sistem navigasi pada internet, hanya yang berbeda 
di sini adalah media yang dipakai keduanya. CD Interaktif memakai media off line berupa CD sementara Internet memakai media on line.

Media pembelajaran saat ini sudah semakin beragam, mulai dari media konvensional seperti buku dan alat peraga tradisional sampai dengan media modern audio visual berupa kaset tape, VCD (Video Compact Disk), maupun alat paraga modern lainnya. Dengan beragam media tersebut, maka suatu sistem pembelajaran yang dapat menghadirkan suasana menyenangkan mutlak diperlukan. Oleh karena itu tidak salah jika CD Interaktif merupakan salah satu alternatif media yang dapat menjawab kebutuhan tersebut.

Menurut praktisi media Augus Savara dalam program e-Lifestyle Metro TV, Sabtu 9 Agustus 2003, kelebihan CD Interaktif antara lain:

- Penggunanya bisa berinteraksi dengan program komputer

- Menambah pengetahuan. Pengetahuan yang dimaksud adalah materi pelajaran yang disajikan CD Interaktif

- Tampilan audio visual yang menarik

Kelebihan pertama yang menyebutkan bahwa penggunanya bisa berinteraksi dengan komputer adalah bahwa dalam CD Interaktif terdapat menu-menu khusus yang dapat diklik oleh user untuk memunculkan informasi berupa audio, visual maupun fitur lain yang diinginkan oleh pengguna. Kemudian yang kedua adalah menambah pengetahuan. Pengetahuan di sini adalah materi pembelajaran yang dirancang kemudahannya dalam CD Interaktif bagi pengguna. Kelebihan ketiga adalah tampilan audio visual yang menarik. Menarik di sini tentu saja jika dibandingkan dengan media konvensional seperti buku atau media dua dimensi lainnya. Kemenarikan di sini utamanya karena sistem interaksi yang tidak dimiliki oleh media cetak (buku) maupun media elektronik lain (film TV, audio).

Dari beberapa keunggulan CD Interaktif, dapat diketahui bahwa CD Interaktif dapat membantu mempertajam pesan yang disampaikan dengan kelebihannya menarik indera dan menarik minat, karena merupakan gabungan antara pandangan, suara, dan gerakan (Suyanto, 2003: 18). Sebagai sebuah produk, CD Interaktif merupakan hasil pemecahan suatu masalah berdasarkan pendekatan komunikasi visual. Rancangan sebuah CD Interaktf adalah sebuah desain komunikasi visual yang ditayangkan melalui monitor yang dapat dihadirkan pada saat tertentu. Layar monitor berfungsi sebagai media komunikasi visual yang tampilannya tidak berbeda dengan desain sebuah majalah atau sebuah surat kabar (Istanto, 2001:55), sehingga kaidah-kaidah perancangan CD Interaktif adalah kaidah-kaidah yang berkaitan dengan desain komunikasi visual.

Penggunaan media komunikasi visual pada posyandu dirancang guna memberikan pembelajaran dan pendidikan berbasis ICT melalui slide show, CD interaktif dan animasi multimedia yang dapat diakses oleh petugas posyandu dalam melakukan pendampingan melalui jaringan internet. Pengembangan sistem ini diharapkan dapat mempercepat pemberian informasi kesehatan pada masyarakat di posyandu dan membantu proses infomabilisasi.

\section{MEDIA PEMBELAJARAN HIDUP SEHAT DI POSYANDU}

Penyuluhan atau pemberian informasi pada masyarakat posyandu merupakan praktek pembelajaran yang cukup menarik, metode dengan pemberian cerama secara konvensional dirasa belum cukup dalam memberikan pemahaman kesehatan. Praktek media pembelajaran merupakan pengembangan metode pembelajaran yang menggabungkan teknologi informasi dengan multimedia pembelajaran melalui CD interaktif dan video animasi melalui media visual seperti Televisi, internet dan projector LCD dengan materi pembelajaran yang diakses secara online dari penggabungan e-learning dan e-health system secara telecenter antar posyandu. Hasil yang diharapkan adalah tersedianya informasi dan penyebaran informasi kesehatan yang termonitoring sesuai dengan standar kesehatan menuju Indonesia sehat 2010 dengan integrasi posyandu di seluruh Indonesia. 

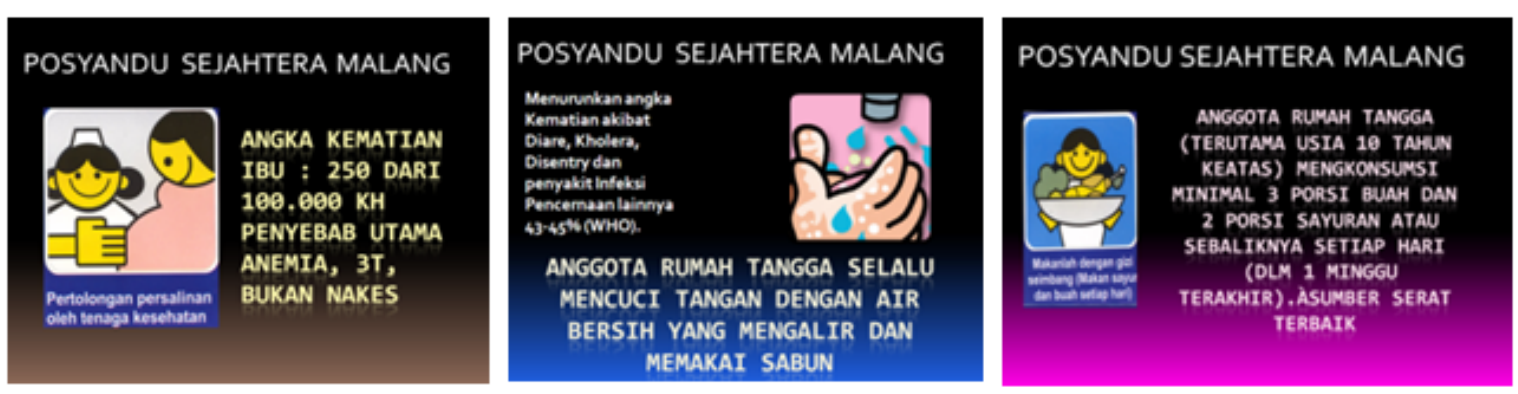

Gambar 1. Media Slide show kesehatan dasar

Salah satu konten dalam bentuk video animasi dan CD interaktif sebagai media pembelajaran secara infomobilisasi dengan melibatkan interaksi pengguna dengan sistem aplikasi yang dibuat. Contoh sebagai berikut :

\section{- Slide Show Learning}

Slide show learning dibuat dengan tujuan pembelajaran pada posyandu menggunakan media aplikasi power point dengan animasi menarik dan tulisan pembelajaran terhadap ibu dan anak. Berikut ini diberikan contoh pembelajaran hidup sehat dan bersih.
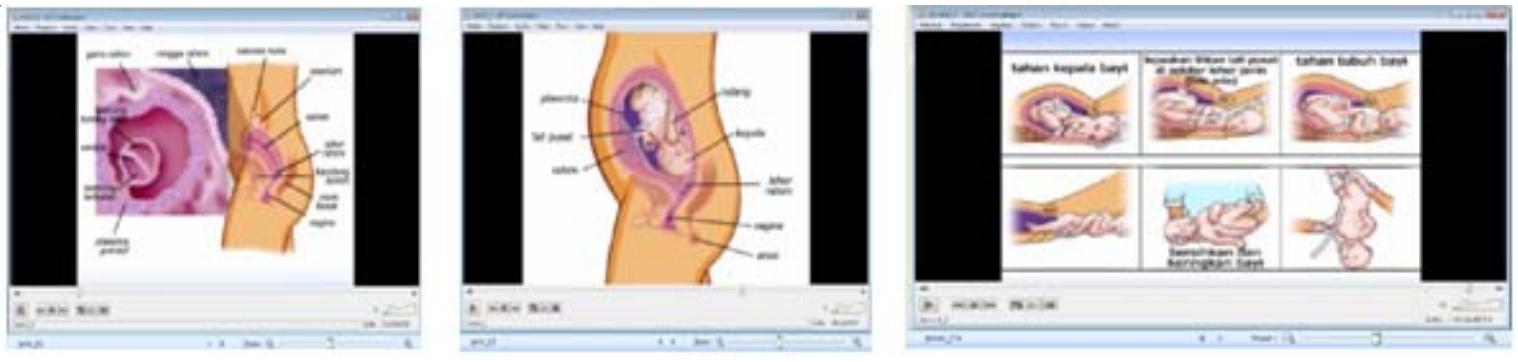

Gambar 2. Video learning kesehatan proses kehamilan

\section{- Video Learning}

Pemanfaatan video learning digunakan dalam pembelajaran posyandu untuk menjelaskan materi yang dianggap sulit oleh penyuluh kesehatan dalam menyampaikan materi. Berbagai video yang ditampilkan dilengkapi dengan animasi dan effek video termasuk sound untuk memaparkan materi agar lebih mudah dicerna oleh ibu-ibu anggota posyandu.Berikut ini diberikan contoh dengan materi proses kehamilan yang sehat
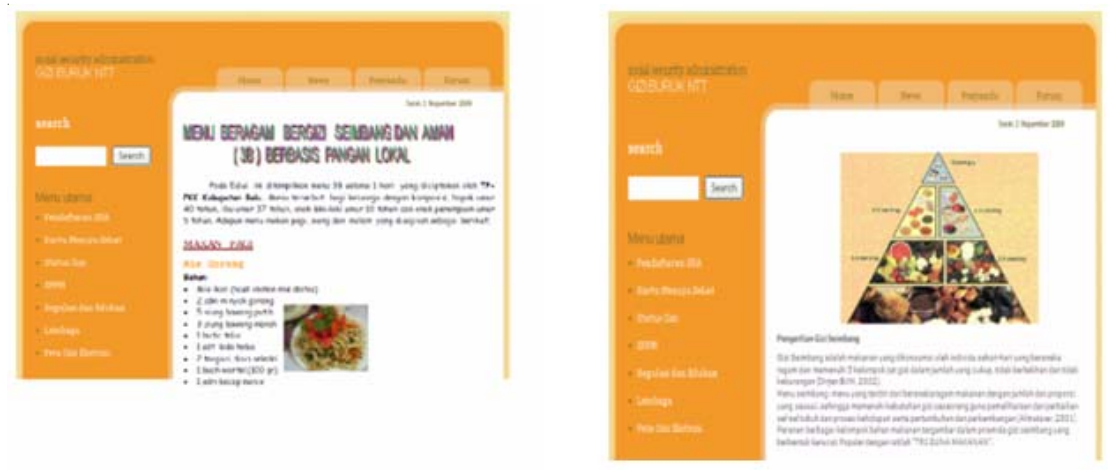

Gambar 3. Website Learning pengolahan makanan kaya gizi 


\section{- Website Learning}

Website learning dimanfaatkan sebagai media pembelajaran pada posyandu.konten dibuat dalam bentuk artikel, paparan maupun tahapan suatu proses sehingga memudahkan penyuluh menjelaskan secara terstrukur dengan materi terupdate secara berkala. Berikut ini contoh konten untuk pembelajaran pengolahan makanan gizi sehat.

\section{PENUTUP}

Pembelajaran di pusat layanan masyarakat dengan memanfaatkan konsep ICT merupakan solusi alternative dalam melakukan praktek pembelajaran kesehatan melalui media komunikasi visual menghasilkan produk-produk media kesehatan yang dapat digunakan oleh fasilitator dan penyuluh kesehatan. Konten dalam bentuk video animasi dan CD interaktif sebagai media pembelajaran secara infomobilisasi dengan melibatkan interaksi pengguna dengan sistem aplikasi yang dibuat slide show learning, video learning, website learning. Dengan tersedianya informasi dan penyebaran informasi kesehatan yang termonitoring sesuai dengan standar kesehatan menuju Indonesia sehat 2010 dengan integrasi posyandu di seluruh Indonesia.

\section{DAFTAR PUSTAKA}

Abidinsyah Siregar, 2009. Penggerakan Perilaku Hidup Bersih Dan Sehat \& Kesehatan Ibu Dan Anak. Makalah pada Temu Kader Menuju Pemantapan Posyandu, mei 2009.

Brown. J, Lewis, R. Harcleroad,F,1985. AV Instruction; Technology, Media, and Methods. McGraw-Hill.

Dembo, Myran H. (1982). Teaching for Learning : Applying Educational Psychology in the classroom. California.

Hackbarth, S,1996. The educational Technology Handbook. Educational Technology Publications, Englewood Cliffs. New Jersey.

Sadiman, dkk , 1990, Media Pendidikan: Pengertian, Pengembangan, dan Pemanfaatannya. CV. Rajawali.

Suparman Atwi, 1997. Model-model Pembelajaran Interaktif. STIA LAN Press. Jakarta.

Teague, F., Rogers, D., Tipling, R, 1994, Technology and Media. Kendall/Hunt Publishing Co. lowa.

Zulfikar Mochamad Rachman, 2008, Panduan Untuk Fasilitator Infomobilisasi.

Mengembangkan Media Komunikasi Berbasis Masyarakat, Tim Partnerships for eProsperity for the Poor (Pe-PP) Bappenas UNDP Jakarta. ISBN : 978-979-3764-23-8. 